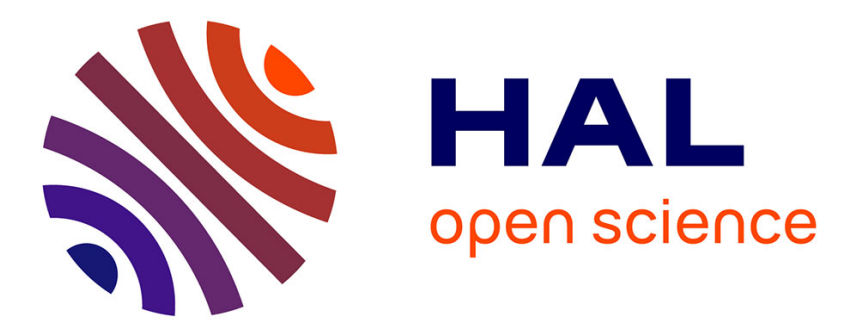

\title{
Prognostic value of jaundice in patients with gallbladder cancer by the AFC-GBC-2009 study group
}

Jean-Marc Régimbeau, D. Fuks, P. Bachellier, Y.P. Le Treut, F.R. Pruvot, F. Navarro, L. Chiche, O. Farges

\section{- To cite this version:}

Jean-Marc Régimbeau, D. Fuks, P. Bachellier, Y.P. Le Treut, F.R. Pruvot, et al.. Prognostic value of jaundice in patients with gallbladder cancer by the AFC-GBC-2009 study group. EJSO - European Journal of Surgical Oncology, 2011, 10.1016/j.ejso.2011.03.135 . hal-00696797

\section{HAL Id: hal-00696797 https://hal.science/hal-00696797}

Submitted on 14 May 2012

HAL is a multi-disciplinary open access archive for the deposit and dissemination of scientific research documents, whether they are published or not. The documents may come from teaching and research institutions in France or abroad, or from public or private research centers.
L'archive ouverte pluridisciplinaire HAL, est destinée au dépôt et à la diffusion de documents scientifiques de niveau recherche, publiés ou non, émanant des établissements d'enseignement et de recherche français ou étrangers, des laboratoires publics ou privés. 


\section{Accepted Manuscript}

Title: Prognostic value of jaundice in patients with gallbladder cancer by the AFC-

GBC-2009 study group

Authors: J.M. Regimbeau, MD, PhD D. Fuks, MD P. Bachellier, MD Y.P. Le Treut, MD

F.R. Pruvot, MD, PhD F. Navarro, MD L. Chiche, MD O. Farges, MD, PhD

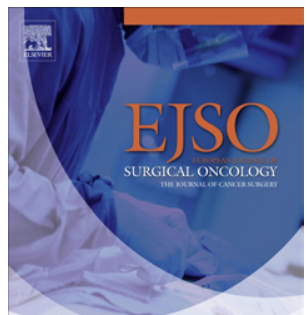

PII: $\quad$ S0748-7983(11)00240-X

DOI: $\quad$ 10.1016/j.ejso.2011.03.135

Reference: YEJSO 3143

To appear in: European Journal of Surgical Oncology

Accepted Date: 28 March 2011

Please cite this article as: Regimbeau JM, Fuks D, Bachellier P, Le Treut YP, Pruvot FR, Navarro

$\mathrm{F}$, Chiche $\mathrm{L}$, Farges $\mathrm{O}$. Prognostic value of jaundice in patients with gallbladder cancer by the AFC-

GBC-2009 study group, European Journal of Surgical Oncology (2011), doi: 10.1016/j.ejso.2011.03.135

This is a PDF file of an unedited manuscript that has been accepted for publication. As a service to our customers we are providing this early version of the manuscript. The manuscript will undergo copyediting, typesetting, and review of the resulting proof before it is published in its final form. Please note that during the production process errors may be discovered which could affect the content, and all legal disclaimers that apply to the journal pertain. 


\section{Prognostic value of jaundice in patients with gallbladder cancer by the AFC-GBC-2009 study group}

JM Regimbeau, MD, PhD 1, D Fuks, MD 1, P Bachellier, MD 2, YP Le Treut, MD ${ }^{3}$, FR Pruvot, MD, $\mathrm{PhD}^{4}{ }^{4}$ F Navarro, MD ${ }^{5}$, L Chiche, MD ${ }^{6}, \mathrm{O}_{\text {Farges, }} \mathrm{MD}, \mathrm{PhD}^{7}$

1, Department of Digestive Surgery. Hôpital Nord, Amiens, France

2, Department of Hepatobiliary Surgery, Hôpital Hautepierre, Strasbourg, France

3, Department of Hepatobiliary Surgery, Hôpital Conception, Assistance-Publique Hôpitaux de Marseille, Marseille, France

4, Department of Hepatobiliary Surgery, Hôpital Claude Huriez, Lille, France

5, Department of Hepatobiliary Surgery, Universitary Hospital, Montpellier, France

6, Department of Hepatobiliary Surgery, Hôpital Côte de Nâcre, Caen, France

7, Department of Hepatobiliary Surgery, Hôpital Beaujon, Assistance-Publique Hôpitaux de Paris, Université Paris 7, Clichy, France

\section{Correspondence:}

Professor J-M. Regimbeau

Department of Digestive Surgery. Amiens North Hospital, University of Picardy Medical Centre, Place Victor Pauchet, F-80054 Amiens Cedex 01, France

Phone: +33 (0)3 22668301 Fax: +33 (0)3 22668680

E-mail: regimbeau.jean-marc@chu-amiens.fr

Word count 2991

Number of references: 20

Number of Figure: 2 of Table: 3

Abbreviations used: GBC: Gallbladder carcinoma; PVE: Portal vein embolization; PD: Pancreaticoduodenectomy. 


\section{ABSTRACT}

Introduction. Jaundice is frequent in patients with gallbladder cancer (GBC) and indicates advanced disease and, according to some teams, precludes routine operative exploration. The present study was designed to re-assess the prognostic value of jaundice in patients with GBC.

Methods. Patients with GBC operated from 1998 to 2008 were included in a retrospective multicenter study (AFC). The main outcome measured was the prognostic value of jaundice in patients with GBC focusing on morbidity, mortality and survival.

Results. 110 of 429 patients with GBC presented with jaundice, with a median age of 66 years (range: 31 - 88). The resectability rate was $45 \%(n=50)$ and the postoperative mortality and morbidity rates were $16 \%$ and $62 \%$, respectively; $71 \%$ had R0 resection and $46 \%$ had lymph node involvement. Overall 1 - and 3-year survivals of the 110 jaundiced patients were $41 \%$ and $15 \%$, respectively. For the 50 resected patients, 1 - and 3-year survivals were $48 \%$ and $19 \%$, respectively (real 5-year survivors $n=4$ ) which were significantly higher than that of the 60 non-resected patients $(31 \%, 0 \%, p=.001)$. Among the resected jaundiced patients, T-stage, $\mathrm{N}$ and $\mathrm{M}$ status were found to have a significant impact on survival. R0 resection did not increase the overall survival in all resected patients, but R0 increased median survival in the subgroup of N0 patients (20 months versus 6 months, $\mathrm{p}=.01$ ).

Conclusion. This series confirms that jaundice is a poor prognostic factor. However, the presence of jaundice does not preclude resection, especially in highly selected patients (N0). 
Key-words: Gallbladder carcinoma; Jaundice; Extended Liver resection; Morbidity, Mortality; Long-term survival 


\section{INTRODUCTION}

Most patients with gallbladder cancer (GBC) still present with advanced tumors (1). The only curative treatment remains resection (2). Jaundice occurs in up to 30 to $50 \%$ of patients with GBC (3-4). Although obstructive jaundice can sometimes be due to concomitant common bile duct stones (5), tumor thrombus (6), or obstruction caused by lymph node involvement, jaundice mostly implies tumor extension to the common bile duct and biliary confluence (7).

The first series focusing on jaundice in patients with GBC was based on 82 patients (3). In this study, only 6 patients were resected with curative intent, and only 4 had negative surgical margins. Their median disease-specific survival was 6 months. In the light of these results, the authors concluded that "These data do not support routine operative exploration of patients with jaundice secondary to gallbladder cancer". However, several series experienced teams did not report such a poor outcome and showed that some jaundiced patients obtained improved survival following resection of GBC (8-12). A subgroup of jaundiced patients may therefore benefit from resection.

This study was designed to re-assess the prognostic value of jaundice on short and longterm outcome of patients undergoing radical surgery for GBC.

\section{METHODS}

\section{Source and selection of patients}

The AFC-GBC-2009 study group, composed of tertiary centers, was created in 2009 under the auspices of the French Association of Surgery (AFC) to produce a retrospective registry of operated GCB patients. Twenty-one centers were asked to: 1/ identify all patients operated for GBC between 1998 and 2008, 2/ fill in a multi-item questionnaire, 3 / return these questionnaires by June 2009 . The protocol was approved 
by the AFC Review Board. Identification of patients was performed by screening the pathology database. The questionnaire was constructed on the basis of the data available in the literature at that time. Investigators were requested to attach an anonymized duplicate of the complete pathology report. All patients who had undergone either curative, palliative or exploratory surgery were further evaluated. Patients were considered to be jaundiced when clinical jaundice was present on initial examination and confirmed by elevated serum bilirubin levels. The diagnosis of GBC was adopted when the pathology report confirmed the presence of adenocarcinoma of biliary origin. Patients with Klatskin tumors or intrahepatic cholangiocarcinoma were excluded from the analysis.

\section{Data review}

If the information could not be retrieved from the medical files, a "not found / not performed" box was available. Coded data were repeatedly checked at random and some pathological data were used as controls. Centers were contacted again when: 1 / some items of the questionnaire had not been answered, 2/ discordant information was present in the questionnaire or between the questionnaire and the pathology report or 3/ last follow-up was less than 6 months.

\section{Criteria studied}

Criteria studied were presented in Table 1. R0 or R1 resections were considered to be curative resections. According to the UICC / AJCC TNM (7th edition 2010) (13), regional lymph nodes (gallbladder, pericholedochal, hepatic pedicle, proper hepatic artery and periportal nodes) were considered to be N1. Involvement of the celiac trunk, superior mesenteric artery and para-aortic lymph nodes was classified as M1 disease. Routine sampling of inter-aortocaval lymph nodes was not performed in this study.

Postoperative hepatic insufficiency was defined by elevation of serum total bilirubin 
level $>2.9 \mathrm{mg} / \mathrm{dL}$ and prothrombin time $<50 \%$ persisting for more than 5 postoperative days (14-15).

\section{Statistical analysis}

Non-parametric data are presented as median (range) and categorical data are presented as frequency and proportion (\%). Categorical data were analyzed using Pearson's chi-square test and the Mann-Whitney U test was used for data not following a normal distribution. Subsequently, Kaplan-Meier survival curves were plotted and log-rank statistics were calculated to assess which variables affected survival time. Significance levels were set at $p<.05$. All statistical tests were performed using SPSS software (version 15.0 for Windows, SPSS Inc., Chicago, IL, USA).

\section{RESULTS}

\section{Demographic data}

Of the 429 patients managed for GBC during this ten-year inclusion period, 110 were jaundiced, corresponding to 43 men and 67 women with a median age of 66 years (range: 31 - 88). No significant difference was observed between jaundiced and nonjaundiced patients in terms of risk factors and co-morbidities (Table 1).

\section{Preoperative management}

At the end of preoperative staging, the rate of suspicion of arterial ( 6 vs. 1\%, $p=.008$ ), portal vein (12 vs. $2 \%, p=.0001$ ) and adjacent organ invasion ( 8 vs. $3 \%, p=.02$ ) on preoperative imaging was significantly higher in jaundiced patients than in nonjaundiced patients.

Histologic evidence of cancer was obtained in 23 jaundiced patients planned for curativeintent resection.

Laparoscopic assessment was performed in 14 jaundiced patients and revealed a 
contraindication to resection in 8 patients consisting in peritoneal carcinomatosis $(n=2)$, liver metastases $(\mathrm{n}=2)$, positive lymph node involvement (site of lymph nodes not specified) $(n=2)$, malignant infiltration of the hepatoduodenal ligament $(n=1)$ and vascular involvement $(\mathrm{n}=1)$. Among 319 non-jaundiced patients, laparoscopic assessment was performed in 24 patients and revealed a contraindication to resection in 6 patients $(p<.04)$.

The median preoperative serum bilirubin level among jaundiced patients was 10.6mg/dl (range: 5.2-38.3). Forty-nine jaundiced patients underwent preoperative biliary drainage (endoscopically 67\%). Drainage-related cholangitis was observed in 6 cases. Seven patients underwent right portal vein embolization (PVE) before scheduled extended right hepatectomy.

Seven patients received neoadjuvant chemotherapy (always gemcitabine-based) and/or radiation therapy and 1 patient received both of these treatment modalities.

\section{Surgical procedures}

A contraindication to resection was discovered in 52 out of 96 patients undergoing laparotomy (Figure 1). Contraindications in the 60 non-resected jaundiced patients (52 after laparotomy and 8 after laparoscopic assessment) were extensive infiltration of the hepatoduodenal ligament $(n=16)$, peritoneal carcinomatosis $(n=11)$, liver metastasis $(\mathrm{n}=8)$, positive lymph node (site of lymph node not specified) $(\mathrm{n}=8)$, vascular involvement $(\mathrm{n}=2)$, presence of cirrhosis $(\mathrm{n}=2)$ and involvement of adjacent organs $(n=4)$. The reason for unresectability was not specified in the questionnaire for 9 patients.

Fifty jaundiced patients underwent curative resection including liver resection in every case (Table 1). A major hepatectomy ( $\geq 3$ segments) was performed in 23 patients including excision of segment I in 6 patients. A lymphadenectomy was associated in 41 
patients, including the hepatoduodenal ligament in all cases, the celiac trunk in 8 cases and the para-aortic area in 3 cases patients. Forty-one jaundiced patients underwent common bile duct resection, and for the other 9 patients, frozen section did not reveal any tumor involvement of the cystic duct. Median operating time was 360 min (range: 90-680) and 23 patients received intra-operative transfusion. The portal vein was resected in 9 patients (of the 13 patients with suspected preoperative portal vein involvement) and one patient had inferior vena cava patch resection. Fourteen jaundiced patients (underwent resection of adjacent organs including 5 pancreaticoduodenectomies (PD) (Table 1). Resectability was significantly lower in jaundiced patients than in non-jaundiced patients ( $45 \%$ vs. $65 \%, p=.001)$. Jaundiced patients had significantly more major hepatectomies (56 vs. 17\%, $p=.0001$ ), more portal vein resections (18 vs. $0.5 \%, p=.0001$ ), more common bile duct resections ( 82 vs. $34 \%$, $p=.0001$ ) and more intraoperative transfusions (46 vs. 23\%, $p=.001$ ) (Table 1). However, no significant difference was observed for resection of adjacent organs, regardless of the organ (28 vs. $29 \%, p=.56)$.

\section{Postoperative outcomes in resected patients (Table 1)}

Mortality and morbidity among resected jaundiced patients ( $n=50)$

The postoperative mortality was $16 \%(n=8)$. The causes of death were: $i /$ acute liver failure ( $n=3)$ after extended right hepatectomy; ii/ sepsis with multiorgan failure $(n=4)$; iii/ respiratory distress syndrome $(n=1)$. All 8 jaundiced patients were older than 65 years and 4 underwent major hepatectomy. No risk factor for postoperative mortality was identified in this subgroup of jaundiced patients.

Thirty-one jaundiced patients experienced a complication after surgery. The most frequent complications were biliary leakage $(n=12)$, pulmonary complications $(n=11)$ and sepsis $(n=9)$ and liver failure $(n=7)$. These complications required an invasive 
procedure in 14 patients (reoperation: $n=4$, radiological drainage: $n=8$, interventional endoscopy: $n=2$ ). The average postoperative hospital stay was 25 days (range: 7-77). On univariate analysis, only preoperative biliary drainage (68 vs. 33\%, $p=.02$ ) was found to be risk factor for postoperative complications in jaundiced patients. In the subgroup of the 21 patients who underwent extended right hepatectomy, preoperative biliary drainage did not significantly increase morbidity in contrast with the 29 patients with minor hepatectomy (83 vs. 38\%, $p=.05$ ).

Mortality and morbidity among all resected patients $(n=257)$

Postoperative mortality and morbidity were $6 \%(n=16)$ and $41 \%(n=105)$, respectively. On univariate analysis, risk factors for mortality were jaundice (16 vs. 4\%, $p=.004$ ), age over 70 years ( 10 vs. $3 \%, p=.04$ ) and common bile duct resection (11 vs. $3 \%, p=.05$ ). Risk factors for morbidity on univariate analysis were jaundice (62 vs. 36\%, $p=.001$ ), preoperative biliary drainage (68 vs. 39\%, $p=.002$ ), portal vein embolization (91 vs. $40 \%, p=.001$ ), major hepatectomy (58 vs. 38\%, $p=.004$ ), adjacent organ resection (53 vs. $38 \%, p=.02$ ), portal vein resection (78 vs. $40 \%, p=.02$ ), common bile duct resection (57 vs. $26 \%, p=.0001$ ) and intraoperative transfusion (52 vs. $36 \%, p=.01$ ).

\section{Pathological data - Predictive Criteria of Resectability}

Among the 50 resected jaundiced patients, 40 had no proof of cancer prior to hepatectomy. Among the 50 resected jaundiced patients, pathological examination of the specimen was available for only 45 patients. Nine patients had T2 tumors, 19 had T3 tumors and 8 had T4 tumors. For 9 patients, T-stage could not be accurately determined from the pathology report. Thirty-two patients had R0 resection. Among the 41 patients who underwent lymphadenectomy, 19 had lymph node involvement, including involvement of lymph nodes in the hepatoduodenal ligament in all patients and paraaorticlymph node involvement in 2 patients. Seventeen tumors were well differentiated 
and 28 were moderately differentiated. Lymph node involvement was more frequent in jaundiced patients (46 vs. 21\%, $p=.02$ ). None of the available preoperative criteria was significantly correlated with R0 resection.

\section{Survival data}

Survival in jaundiced patients $(n=110)$

One-, 3- and 5-year overall survival rates for the 110 jaundiced patients were $41 \%, 15 \%$ and $13 \%$, respectively.

Survival in resected jaundiced patients $(n=50)$

One-, 3- and 5-year survival rates for the 50 resected jaundiced patients were $48 \%, 19 \%$ and $19 \%$, respectively i.e. significantly different from those of non-resected jaundiced patients $(31 \%, 0 \%$ and $0 \%, p=.001)$. Among the resected jaundiced patients, $\mathrm{T}$-stage, $\mathrm{N}$ and M status were found to have a significant impact on survival (Table 2). R0 resection did not increase survival in the overall population of resected patients (Table 2), but R0 increased median survival in the subgroup of N0 patients (20 versus 6 months, $p=.01$ ). All resected patients with T4, N1 or M1 tumors died within the first 3 postoperative years. Eleven resected jaundiced patients were N0R0: 3 patients died postoperatively, 4 survived 12,15, 20, 22 months, and the remaining 4 patients were real survivors at 5 years. Among these 4 patients, tumor stage was T2 for 2 patients and T3 for the other 2 patients. All of these patients underwent common bile duct resection and 3 underwent in addition resection of duodenum, stomach and portal vein. All these patients had N0 and R0 margins.

Survival in all resected patients with gallbladder cancer $(n=257)$

Among all resected patients with gallbladder cancer, jaundice was found to have a negative impact on prognosis (Figure 2). Median survival in the presence of jaundice was poorer that of non-jaundiced patients (11 vs. 36 months; $p<.0001)$. 


\section{DISCUSSION}

\section{Jaundice is an indicator of advanced disease}

Most studies have reported that jaundice is an indicator of advanced disease with a dismal prognosis in GBC. The results of the present study, which is one of the largest studies, confirmed that jaundiced patients had more advanced tumors and poorer 3year survival than non-jaundiced patients (19\% and 50\%, respectively). The first study focusing on jaundice (3), published by a reference team, reported a 7\% resectability rate, a 5\% R0 margin rate and poor survival (2-year disease-free survival of $0 \%$, median disease-specific survival of 6 months). These results, emphasizing the fact that resection should not be proposed in patients with GBC associated with jaundice, were largely diffused in the medical community.

\section{Jaundice should not be considered as an absolute contraindication}

However, it should be stressed that one of the major criteria (i.e., R0 resection) proposed as a contraindication to resection appears to be over estimated: the $5 \% \mathrm{R} 0$ resection margin rate was calculated on the whole population of 82 patients and not on the population of resected patients. The real R0 resection rate in the series of Hawkins et al. was actually $67 \%$ ( 4 out of 6 resected patients). Several series also did not report such a poor outcome, with much higher resectability rates ranging from 7 to $53 \%$, and R0 resection margin rates ranging from 15 to $100 \%(\mathbf{8 - 1 2})$ (Table 3). In the present series, the resectability rate was $45 \%$ and the R0 resection rate was $58 \%$. The resectability rate was higher in non-jaundiced patients ( $64 \%$ vs. $45 \%)$, but no significant difference of R0 resection rate was observed between jaundiced and non-jaundiced patients ( $71 \%$ vs. $86 \%)$. Agarwal et al. did not observe any difference in terms of resectability between resected jaundiced and non-jaundiced patients $(27 \%$ vs. $36 \%$, 
$p>$.05) (11). The results in terms of resectability can be (artificially) improved by more widespread use of laparoscopic assessment (16-17) especially in jaundiced patients scheduled for surgery due to its accuracy (57\%).

\section{Some jaundiced patients appeared to benefit from surgery}

Moreover, in the same series (8-12), some jaundiced patients appeared to benefit from surgery in terms of survival following resection: with a mean 3-year survival of $20 \%$ and some real survivors at 3 and 5 years $(\mathbf{8}, \mathbf{1 1})$, results never obtained in the subgroup of non-resected jaundiced patients. In the present series, overall survival was better in resected jaundiced patients than in non-resected jaundiced patients $(p=.001)$ and the 3year overall survival rates of $19 \%$ was comparable to the overall survival of resected patients with pancreatic adenocarcinoma in whom the principle of curative R0 resection has been established.

\section{Routine sampling of lymph nodes should be performed}

The long-term results can also be improved. Firstly, routine sampling of inter-aortocaval lymph nodes was not performed in this study and it is likely that some patients in the subgroup of resected jaundiced patients and poor long-term survival were positive for inter-aortocaval lymph nodes. Inter-aortocaval lymph node sampling must be performed systematically in this setting in order to contraindicate resection. Similarly, in this series, regardless of T-stage, all patients with long-term survival had N0 disease and underwent R0 resection. The results of this study emphasize that hepatic pedicle lymph node sampling may be performed as a routine examination before resection in jaundiced patients with GBC in order to avoid useless surgery in patients with N+ disease (no survivors with N1 disease at 3years). The presence of lymph node involvement has been reported to be a poor prognosis factor by other authors, even in jaundiced patients $(3,11)$. Secondly, only $29 \%$ of patients with GBC had adjuvant 
therapy in the French nationwide survey of GBC (data not shown) (4). A phase III study analysing the effect of adjuvant chemotherapy (Gem0x 85) in patients with R0/R1 resection for bile duct cancer is currently underway in France (ACCORD 18/0803 protocol). Inclusion of patients in this study will allow us to address the issue of adjuvant chemotherapy.

Postoperative morbidity and mortality may be decreased by minor resections and careful selection of patients requiring preoperative biliary drainage

However, these encouraging results in terms of survival in resected jaundiced patients were achieved at the price of postoperative mortality and morbidity of $16 \%$ and $62 \%$. The postoperative mortality rate was mainly (50\%) due to liver failure and higher among elderly patients after major hepatectomy. In the present series, $46 \%$ of patients underwent major hepatectomy. This mortality rate was similar to the mortality observed in other series in which major hepatectomy was performed $(\mathbf{3}, \mathbf{8 - 9}, \mathbf{1 8})$ (Table 3). Our surgical practices need to be modified, as it has been reported that the extent of hepatectomy is not related to R0 rate and long-term survival $(4,19)$. Secondly, a parenchymal preservation strategy must be investigated in this setting in the light of the results published by Agarwal et al.: in this series of 14 resected jaundiced patients, 13 patients underwent segment IVB-V liver resection with a very low (one patient) mortality, 100\% R0 resection rate, and meaningful prolongation of survival (11). A similar strategy of minor resection has been recently published by Chen et al. for hilar cholangiocarcinoma with similar results (20). On univariate analysis, only preoperative biliary drainage (68 vs. $33 \%, p=.02$ ) was found to be a risk factor for postoperative complications in jaundiced patients. In the subgroup of 21 patients who underwent extended right hepatectomy, preoperative biliary drainage did not significantly increase morbidity in contrast with the 29 patients treated by minor hepatectomy (83 vs. 38\%, 
$p=.05$ ). In summary, the morbidity and mortality after resection in jaundiced patients with GBC could possibly be decreased by performing more minor resections and by carefully selecting patients requiring preoperative biliary drainage (especially elderly patients).

\section{Limitations of the study}

Certainly, there are limitations to a retrospective analysis conducted on patients treated over a long time interval. Despite the large number of patients included in the study, this was a highly selected cohort, representing only a fraction of the total number of jaundiced patients with GBC diagnosed during the study period. However, by including patients treated at 21 different surgical centers, our results may be less subject to selection bias than previously reported single-institution experiences and may better represent common practice.

\section{Conclusion}

The presence of jaundice in patients with GBC does not necessarily indicate inoperability and the decision to contraindicate the only available curative treatment in these patients must be taken very carefully. After laparoscopy and systematic interaortocaval sampling, the population of patients most likely to benefit from surgery must be identified: the subgroup of patients with NO disease (routine sampling of hepatic pedicle lymph nodes must be evaluated) treated by R0 resection. The results of operative management of jaundiced patients need to be improved in order to decrease the postoperative morbidity and mortality. 


\section{Authors' contributions:}

All authors are justifiably credited with authorship. In detail:

Study conception and design: JM Regimbeau, O Farges, FR Pruvot

Data acquisition: all authors

Data analysis and interpretation: D Fuks, JM Regimbeau, O Farges

Drafting of the manuscript: JM Regimbeau, D Fuks

Critical revision of the manuscript: JM Regimbeau, O Farges, D Fuks

Supervision: JM Regimbeau, O Farges

All authors agree with the submission and have given their final approval.

\section{* Acknowledgments:}

The authors would like to thank Delphine Lignier and the following surgeons who included patients in the study: They would also like to thanks all authors of the AFCGBC-2009 study group who contributed equally to this manuscript: J Hardwigsen (Hôpital de la Conception, Marseille), P Pessaux (Hôpital Hautepierre, Strasbourg), J Belghiti (Hôpital Beaujon, Clichy), C Ducerf (Hôpital de la Croix Rousse, Lyon), E Boleslawski (Hôpital Huriez, Lille), D Cherqui (Hôpital Henri Mondor, Créteil), A Laurent (Hôpital Henri Mondor, Créteil), G Mantion (CentreHospitalier Universitaire, Besançon), H B de la Batte (Centre Hospitalier de Rio), J Lubrano (CentreHospitalier Universitaire, Besançon), B Suc (CentreHospitalier Universitaire, Toulouse), G Fourtanier (CentreHospitalier Universitaire, Toulouse), G Nuzzo (Université Catholique de Rome), D Bertrand (Hôpital de Jolimont-Lobbes, Belgique), D Dili (Hôpital de Jolimont-Lobbes, Belgique), N Dehni (CentreHospitalier Universitaire, Brest), O Soubrane (Hôpital Cochin, Paris), O Scatton (Hôpital Cochin, Paris), C Letoublon (CentreHospitalier Universitaire, 
Grenoble), D Badic (CentreHospitalier Universitaire, Grenoble), M Scotte (Hôpital Charles Nicolle, Rouen).

\section{Conflicts of interest:}

None of the authors have any financial or personal relationships with other people or organizations that could inappropriately influence (bias) this work.

\section{Responsibility:}

This multicenter study is an original work not submitted to any other journal. The corresponding author had full access to all data in the study and has final responsibility for the decision to submit for publication. 


\section{REFERENCES}

1. Donohue JH. Present status of the diagnosis and treatment of gallbladder carcinoma. J Hepatobiliary Pancreat Surg 2001;8:530-4.

2. Fong Y, Jarnagin W, Blumgart LH. Gallbladder cancer: comparison of patients presenting initially for definitive operation with those presenting after prior noncurative intervention. Ann Surg 2000;232:557-69.

3. Hawkins WG, DeMatteo RP, Jarnagin WR, Ben-Porat L, Blumgart LH, Fong Y. Jaundice predicts advanced disease and early mortality in patients with gallbladder cancer. Ann Surg Oncol 2004; 11:310-5.

4. Regimbeau JM, Farges 0, Pruvot FR. Chirurgie des cholangiocarcinomes intrahépatiques, hilaires et vésiculaires. Monographie de l'Association Française de Chirurgie. Springer-Verlag Paris 2009

5. Redaelli CA, Büchler MW, Schilling MK, Krähenbühl L, Ruchti C, Blumgart LH, Baer HU. High coincidence of Mirizzi syndrome and gallbladder carcinoma. Surgery 1997;121:5863.

6. Rau C, Marec F, Vibert E, Geslin G, Yzet T, Joly JP, Chatelain D, Duval H, Regimbeau JM. Gallbladder cancer revealed by a jaundice caused by an endobiliary tumor thrombus. Ann Chir. 2004;129:368-71.

7. Shimizu Y, Ohtsuka M, Ito H, Kimura F, Shimizu H, Togawa A, Yoshidome H, Kato A, Miyazaki M. Should the extrahepatic bile duct be resected for locally advanced gallbladder cancer? Surgery 2004;136:1012-7.

8. Kondo S, Nimura Y, Kamiya J, Nagino M, Kanai M, Uesaka K, Yuasa N, Sano T, Hayakawa N. Factors influencing postoperative hospital mortality and long-term survival after radical resection for stage IV gallbladder carcinoma. World J Surg 2003; $27: 272-7$. 
9. Miyazaki M, Itoh H, Ambiru S, Shimizu H, Togawa A, Gohchi E, Nakajima N, Suwa T. Radical surgery for advanced gallbladder carcinoma. Br J Surg 1996; 83:478-81.

10. Todoroki T, Takahashi H, Koike N, Kawamoto T, Kondo T, Yoshida S, Kashiwagi H, Otsuka M, Fukao K, Saida Y. Outcomes of aggressive treatment of stage IV gallbladder cancer and predictors of survival. Hepatogastroenterology 1999;46:2114-21.

11. Agarwal AK, Mandal S, Singh S, Bhojwani R, Sakhuja P, Uppal R. Biliary obstruction in gall bladder cancer is not sine qua non of inoperability. Ann Surg Oncol 2007;14:2831-7. 12. Varma V, Gupta S, Soin AS, Nundy S. Does the presence of jaundice and/or a lump in a patient with gall bladder cancer mean that the lesion is not resectable? Dig Surg 2009;26:306-11.

13. Edge SB. American Joint Committee on Cancer: AJCC cancer staging manual. 7th ed. New York: Springer; 2010.

14. Paugam-Burtz C, Janny S, Delefosse D, Dahmani S, Dondero F, Mantz J, Belghiti J. Prospective validation of the "fifty-fifty" criteria as an early and accurate predictor of death after liver resection in intensive care unit patients. Ann Surg 2009;249:124-8.

15. Balzan S, Belghiti J, Farges O, Ogata S, Sauvanet A, Delefosse D, Durand F. The "50-50 criteria" on postoperative day 5: an accurate predictor of liver failure and death after hepatectomy. Ann Surg 2005;242:824-8.

16. D'Angelica M, Fong Y, Weber S, Gonen M, DeMatteo RP, Conlon K, Blumgart LH, Jarnagin WR. The role of staging laparoscopy in hepatobiliary malignancy: prospective analysis of 401 cases. Ann Surg Oncol 2003;10:183-9

17. Fuks D, Regimbeau JM. Role of exploratory laparoscopy in hepato-biliary malignancies. J Chir (Paris) 2008;145:16-9. 
18. Nishio H, Nagino M, Ebata T, Yokoyama Y, Igami T, Nimura Y. Aggressive surgery for stage IV gallbladder carcinoma; what are the contraindications? J Hepatobiliary Pancreat Surg 2007;14:351-7.

19. Goetze TO, Paolucci V. Benefits of reoperation of T2 and more advanced incidental gallbladder carcinoma: analysis of the German registry. Ann Surg 2008 ;247:104-8.

20. Chen XP, Lau WY, Huang ZY, Zhang ZW, Chen YF, Zhang WG, Qiu FZ. Extent of liver resection for hilar cholangiocarcinoma. Br J Surg 2009;96:1167-75. 
Table 1. Demographic data of jaundiced $(n=110)$ and non-jaundiced patients $(n=319)$ with gallbladder cancer

\begin{tabular}{|c|c|c|c|}
\hline & $\begin{array}{c}\text { Jaundiced } \\
n\end{array}$ & $\begin{array}{c}\text { Non-jaundiced } \\
n\end{array}$ & $p$-value \\
\hline Male gender & 43 & 96 & .06 \\
\hline Age more than 70 years & 40 & 108 & .54 \\
\hline Resectability & 50 & 207 & .001 \\
\hline \multicolumn{4}{|l|}{ Extent of liver resection } \\
\hline $\begin{array}{l}\text { - } \quad \text { Major hepatectomy (>3 segments) } \\
\text { - } \quad \text { Anatomical segments IVa V } \\
\text { - } \quad \text { Extended right hepatectomy } \\
\text { - } \quad \text { Central hepatectomy } \\
\text { - } \quad \text { Extended left hepatectomy } \\
\end{array}$ & $\begin{array}{c}23 \\
16 \\
11 \\
21 \\
2 \\
0 \\
0\end{array}$ & $\begin{array}{c}36 \\
118 \\
57 \\
21 \\
4 \\
5 \\
2 \\
\end{array}$ & .0001 \\
\hline \multicolumn{4}{|l|}{ Other procedures } \\
\hline $\begin{array}{r}\text { - } \quad \text { Lymphadenectomy } \\
\text { - } \quad \text { Portal vein resection } \\
\text { - } \quad \text { Common bile duct resection } \\
\text { - Adjacent organ resection } \\
\text { Peritoneal carcinomatosis } \\
\text { Colectomy } \\
\text { Gastric resection } \\
\text { Pancreaticoduodenectomy } \\
\text { Duodenal resection } \\
\text { Nephrectomy } \\
\text { Diaphragm resection } \\
\text { Adrenalectomy }\end{array}$ & $\begin{array}{l}41 \\
9 \\
4 \\
41 \\
14 \\
3 \\
3 \\
6 \\
5 \\
2 \\
0 \\
0 \\
0 \\
\end{array}$ & $\begin{array}{c}172 \\
1 \\
1 \\
71 \\
60 \\
5 \\
15 \\
2 \\
5 \\
8 \\
1 \\
1 \\
1\end{array}$ & $\begin{array}{l}.50 \\
.0001 \\
.05 \\
.0001 \\
.56\end{array}$ \\
\hline - Vascular clamping & 29 & 78 & .01 \\
\hline - Intra-operative transfusion & 23 & 48 & .001 \\
\hline Mortality (number of patients) & 8 & 8 & .004 \\
\hline Complications (number of patients) & 31 & 74 & .001 \\
\hline $\begin{array}{ll} & \text { Biliary leakage } \\
- & \text { Liver failure } \\
- & \text { Sepsis } \\
-\quad & \text { Pleural effusion / lung infection } \\
& \text { Hemorrhage } \\
\end{array}$ & $\begin{array}{c}12 \\
7 \\
9 \\
11 \\
0 \\
\end{array}$ & $\begin{array}{c}36 \\
7 \\
25 \\
20 \\
2 \\
\end{array}$ & \\
\hline \multicolumn{4}{|l|}{ Management of postoperative complications } \\
\hline $\begin{array}{ll}\text { - } & \text { Re-operation } \\
\text { - } & \text { Percutaneous drainage } \\
\end{array}$ & $\begin{array}{c}4 \\
10\end{array}$ & $\begin{array}{c}7 \\
14\end{array}$ & $\begin{array}{l}.17 \\
.04\end{array}$ \\
\hline
\end{tabular}


Table 2. Prognostic factors in resected jaundiced patients $(n=50)$ (univariate analysis)

\begin{tabular}{|c|c|c|c|c|c|}
\hline & $\mathbf{n}$ & $\begin{array}{c}\text { 1-year } \\
\text { survival }\end{array}$ & $\begin{array}{c}\text { 3-year } \\
\text { survival }\end{array}$ & $\begin{array}{c}\text { 5-year } \\
\text { survival }\end{array}$ & $p$-value \\
\hline Gender & $\begin{array}{l}29 \\
21 \\
\end{array}$ & $\begin{array}{l}49 \% \\
48 \% \\
\end{array}$ & $\begin{array}{l}11 \% \\
36 \% \\
\end{array}$ & $\begin{array}{l}11 \% \\
36 \% \\
\end{array}$ & .99 \\
\hline Biliary drainage & $\begin{array}{l}22 \\
28 \\
\end{array}$ & $\begin{array}{l}58 \% \\
41 \% \\
\end{array}$ & $\begin{array}{l}12 \% \\
18 \% \\
\end{array}$ & $\begin{array}{l}12 \% \\
18 \% \\
\end{array}$ & .84 \\
\hline $\begin{array}{rr}\text { Major hepatectomy } & \\
& \text { No } \\
& \text { Yes } \\
\end{array}$ & $\begin{array}{l}22 \\
28 \\
\end{array}$ & $\begin{array}{l}60 \% \\
39 \% \\
\end{array}$ & $\begin{array}{l}25 \% \\
14 \% \\
\end{array}$ & $\begin{array}{l}25 \% \\
13 \% \\
\end{array}$ & .15 \\
\hline $\begin{array}{r}\text { Main bile duct resection } \\
\text { No } \\
\text { Yes } \\
\end{array}$ & $\begin{array}{r}9 \\
41 \\
\end{array}$ & $\begin{array}{l}45 \% \\
47 \% \\
\end{array}$ & $\begin{array}{c}0 \% \\
18 \% \\
\end{array}$ & $\begin{array}{c}0 \% \\
18 \% \\
\end{array}$ & .76 \\
\hline $\begin{array}{r}\text { Portal vein resection } \\
\text { No } \\
\text { Yes } \\
\end{array}$ & $\begin{array}{c}41 \\
9 \\
\end{array}$ & $\begin{array}{l}51 \% \\
41 \% \\
\end{array}$ & $\begin{array}{l}17 \% \\
13 \% \\
\end{array}$ & $\begin{array}{l}17 \% \\
13 \% \\
\end{array}$ & .48 \\
\hline T-stage * & $\begin{array}{c}9 \\
19 \\
8 \\
\end{array}$ & $\begin{array}{c}77 \% \\
34 \% \\
0 \% \\
\end{array}$ & $\begin{array}{c}23 \% \\
0 \% \\
0 \% \\
\end{array}$ & $\begin{array}{c}23 \% \\
0 \% \\
0 \% \\
\end{array}$ & .02 \\
\hline $\begin{array}{l}\text { N0 } \\
\text { N1 }\end{array}$ & $\begin{array}{l}26 \\
19 \\
\end{array}$ & $\begin{array}{l}66 \% \\
42 \% \\
\end{array}$ & $\begin{array}{c}31 \% \\
0 \% \\
\end{array}$ & $\begin{array}{c}31 \% \\
0 \% \\
\end{array}$ & .03 \\
\hline $\begin{array}{l}\text { M0 } \\
\text { M1 } \\
\end{array}$ & $\begin{array}{c}43 \\
7 \\
\end{array}$ & $\begin{array}{c}56 \% \\
0 \% \\
\end{array}$ & $\begin{array}{c}22 \% \\
0 \% \\
\end{array}$ & $\begin{array}{c}22 \% \\
0 \% \\
\end{array}$ & .03 \\
\hline $\begin{array}{rr}\text { Surgical margins } * \text { Hै } & \\
& \mathrm{R} 0 \\
\mathrm{R} 1 \\
\end{array}$ & $\begin{array}{l}32 \\
13 \\
\end{array}$ & $\begin{array}{l}2 \% \\
50 \% \\
\end{array}$ & $\begin{array}{l}9 \% \\
0 \% \\
\end{array}$ & $\begin{array}{l}9 \% \\
0 \% \\
\end{array}$ & .24 \\
\hline
\end{tabular}

* Pathological examination was available for only 45 patients.

T-stage was not available in the pathology report for 9 patients.

If Surgical margins were analyzed in all patients regardless of $\mathrm{N}$ status. 
Table 3. Resectability and survival in jaundiced patients in the literature

\begin{tabular}{|c|c|c|c|c|c|c|c|}
\hline Author (inclusion period) & $\begin{array}{c}\text { Jaundiced } \\
\text { patients (n) }\end{array}$ & $\begin{array}{c}\text { Resectabilit } \\
\mathbf{y} \\
\mathbf{n}(\%)\end{array}$ & $\begin{array}{c}\mathrm{R} 0 \text { resection } \\
\%\end{array}$ & $\begin{array}{c}\text { Major } \\
\text { resection } \\
\% \\
\end{array}$ & $\begin{array}{c}\text { Mortality } \\
\%\end{array}$ & $\begin{array}{c}\text { Lymph node } \\
\text { involvement } \\
\%\end{array}$ & $\begin{array}{c}\text { Survivors at } 3 \\
\text { years n(\%) }\end{array}$ \\
\hline Hawkins (1995-2002) ${ }^{3}$ & 82 & $6(7 \%)$ & $67^{*}$ & 67 & 33 & - & $0(0)$ \\
\hline Agarwal (2001-2003) 11 & 95 & $14(15 \%)$ & 100 & 7 & 7 & 78 & 2 \\
\hline Nishio (1977-2004) 18 & 96 & $51(53 \%)$ & 100 & - & 35 & - & $(41)$ \\
\hline Todoroki (1976-1997) 10 & - & 61 & 15 & $19^{* *}$ & 13 & - & - \\
\hline Kondo (1979-1997) ${ }^{8}$ & 48 & - & 100 & 100 & 27 & 75 & $7(22)$ \\
\hline Varma $(1996-2003)^{12}$ & 62 & $(49 \%)^{* * *}$ & $50 * * *$ & $12^{* * *}$ & & - & - \\
\hline Present study (1998-2008) & 110 & $50(45 \%)$ & 58 & 46 & 16 & 38 & $4(19)$ \\
\hline
\end{tabular}

* 4 patients had R0 margins among 6 resected patients

** including non-jaundiced patients with stage IV

*** including patients with abdominal mass 
Figure 1. Study synopsis

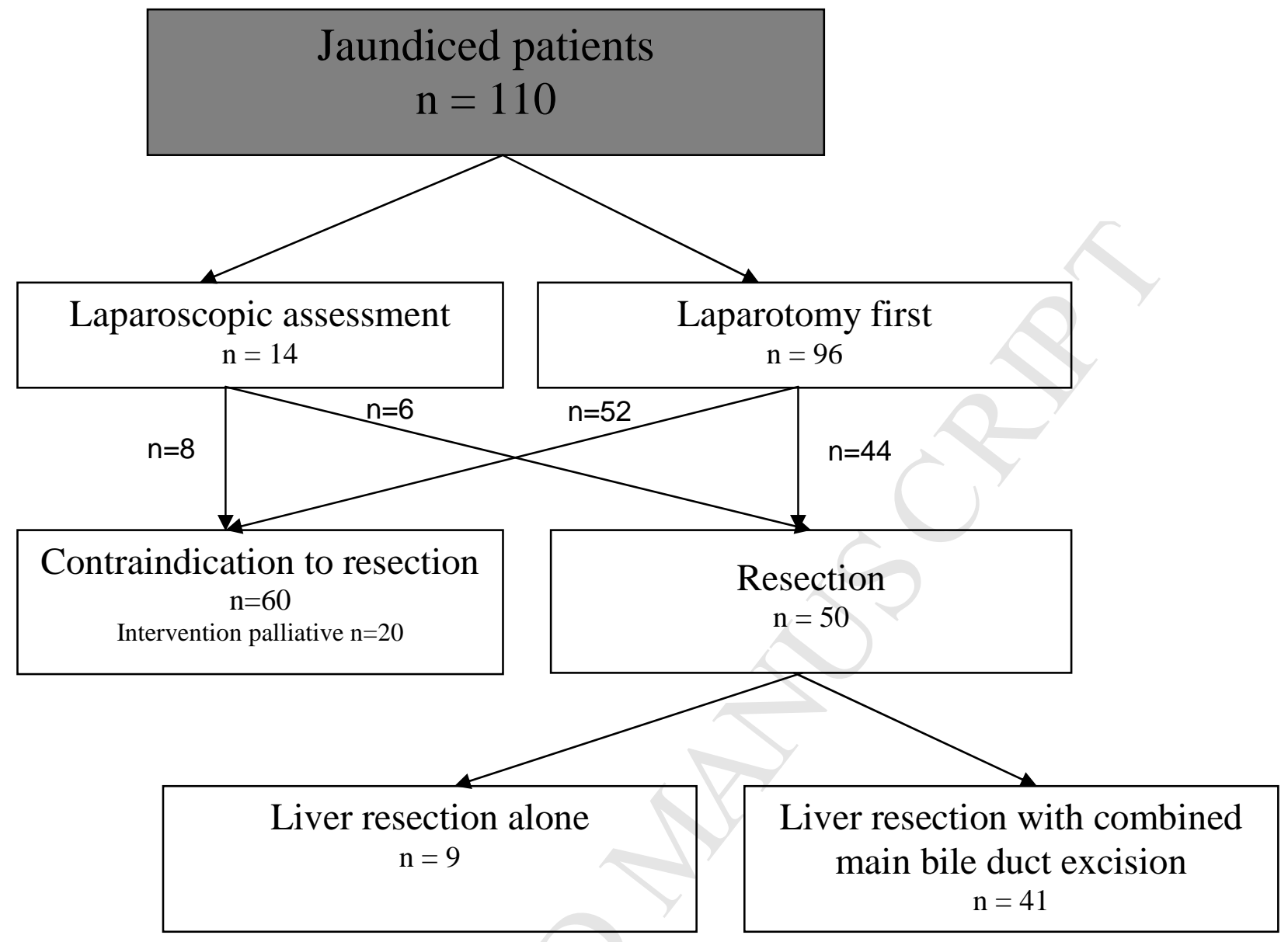


Figure 2. Overall survival of patients resected for gallbladder carcinoma with (green) or without jaundice (blue).

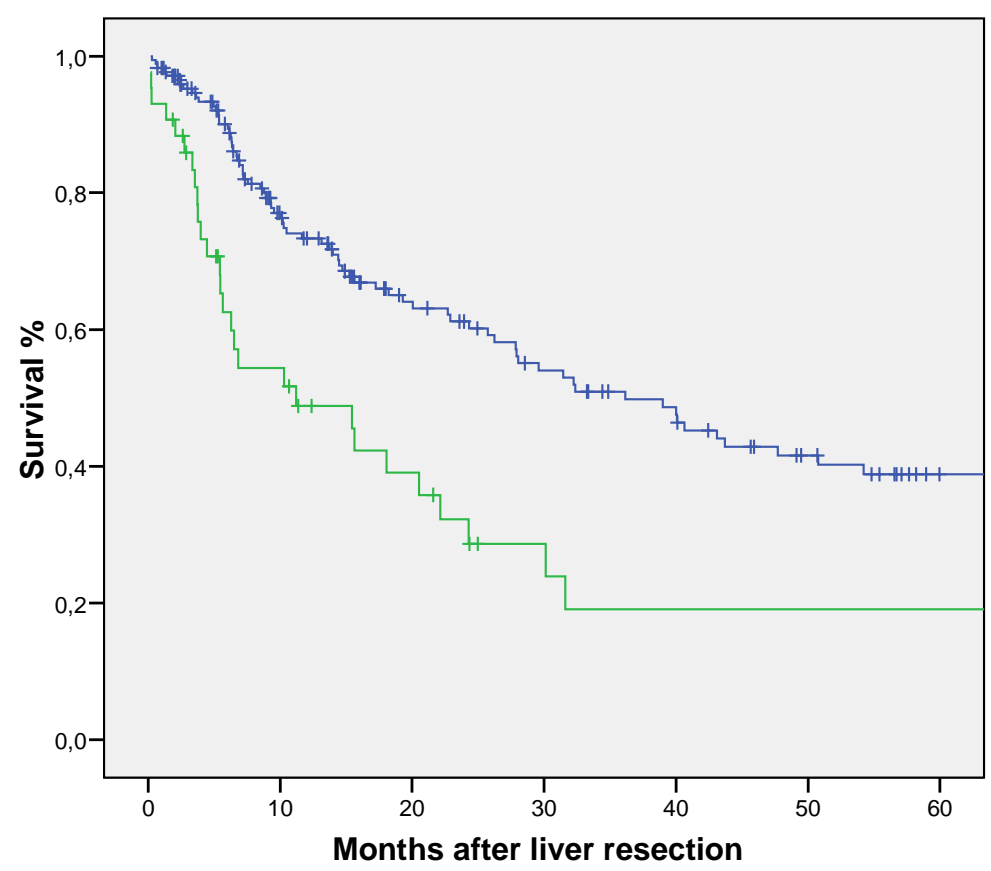

Jaundice

\begin{tabular}{|c|c|c|c|}
\hline & 1 -year & 3 -year & 5 -year \\
\hline Survival & $48 \%$ & $19 \%$ & $19 \%$ \\
\hline Patients exposed & $\mathrm{n}=16$ & $\mathrm{n}=4$ & $\mathrm{n}=4$ \\
\hline
\end{tabular}

No Jaundice

\begin{tabular}{|c|c|c|c|}
\hline & 1 -year & 3-year & 5 -year \\
\hline Survival & $73 \%$ & $50 \%$ & $38 \%$ \\
\hline Patients exposed & $\mathrm{n}=97$ & $\mathrm{n}=45$ & $\mathrm{n}=19$ \\
\hline
\end{tabular}




\section{Conflicts of interest:}

None of the authors have any financial or personal relationships with other people or organizations that could inappropriately influence (bias) this work. 